\title{
ÁREAS HABITACIONALES Y FUNERARIAS EN EL NEOLÍTICO DE LA CUENCA INTERIOR DEL TAJO: LA PROVINCIA DE TOLEDO
}

\author{
HABITATION AREAS AND FUNERAL AREAS IN THE NEOLITHIC OF THE INLAND \\ TAGUS BASIN: THE PROVINCE OF TOLEDO
}

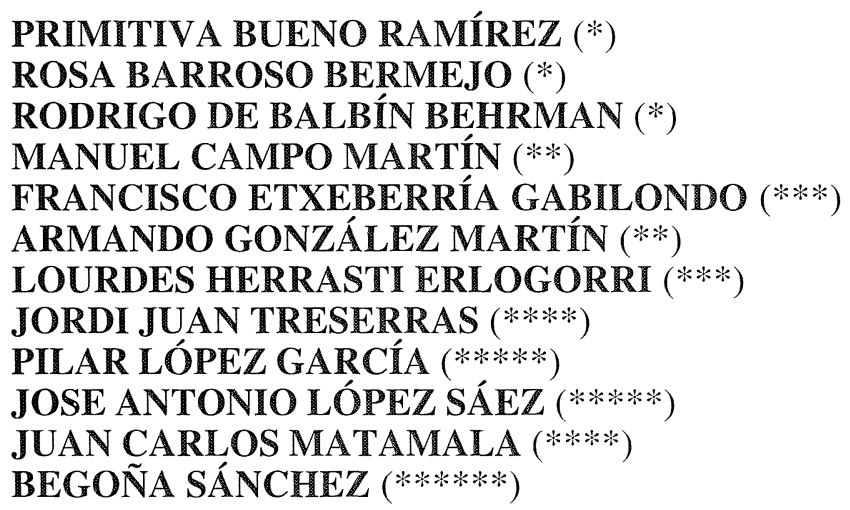

\section{RESUMEN}

Se plantea una reflexión sobre las implicaciones sociales, culturales y cronológicas del mundo funerario al interior del Tajo. Concretamente los datos de la provincia de Toledo; analizados desde los yacimientos del dolmen de Azután y del túmulo del Castillejo, plantean la contemporaneidad de distintas versiones arquitectónicas en el megalitismo antiguo peninsular y la asociación manifiesta entre hábitats y sepulturas.

Los nichos económicos, fundamentalmente dehesas cultivadas con zonas aclaradas para la siembra de cereal y para los pastos de los animales, abogan por proponer una economía mixta en un modelo de explotación campesina protagonizado por grupos que acuden de modo recurrente a los mismos lugares desde los momentos más antiguos del Neolítico hasta la Edad del Bronce.

\footnotetext{
(*) Área de Prehistoria. Universidad de Alcalá de Henares

(***) Dpto de Biología. Unidad de Antropología. U.A.M

(***) Sociedad de Ciencias Aranzadi. San Sebastián.

(****) Universidad Autónoma de Barcelona.

(******) Laboratorio Arqueobotánica. Instituto de Historia. CSIC. Madrid.

(*******) Museo Nacional de Ciencias Naturales. CSIC. Madrid.

Recibido: 2-VII-02; aceptado: 30-IX-(02.
}

\section{ABSTRACT}

This paper offers a reflection on the social, cultural and chronological implications of the funeral world of the inland Tagus basin. In particular the data of the province of Toledo, analysed from the site of the megaliths of Azutan and the burial mound of the Castillejo, allows us to propose the contemporaneity of several architectural types in the early Megalithic culture of Iberia and the association between ha bitats and graves.

The economic niches, mainly cultivated meadows with areas for sowing grain and pasture for animals, suggest the existence of a mixed economy in a peasant society practised by groups who returned to the same places from the earliest moments of the Neolithic to the Bronze Age.

Palabras clave: Meseta Sur. Cultura megalítica. Hábitat. Enterramiento. Neolítico. Economía mixta.

Key words: Southern Meseta. Megalithic culture. Habitat. Burials. Neolithic. Mixed economy.

\section{INTRODUCCIÓN}

La imagen de una España interior seca y fría, prácticamente despoblada durante el neolítico y, 
desde luego, sin presencia megalítica o con algún ejemplo esporádico y tardío (Osuna Ruiz 1975), comenzó a deshacerse con los trabajos del equipo de Delibes en la Meseta Norte y con los que nosotros, en una dimensión más modesta, emprendimos en la Meseta Sur. La investigación desde los años 80 hasta la actualidad ha ido diseñando un panorama complejo con multitud de megalitos y, lo que es más interesante, con túmulos sin estructura megalítica y otras formas paramegalíticas que demuestran un polimorfismo fehaciente en los enterramientos colectivos del interior peninsular. Las fechas sin calibrar de estas estructuras abarcan desde el VI al IV milenio BP.

A ello se suman las evidencias, cada vez mayores, de habitats asociados a estos enterramientos con lo que las áreas funerarias se están convirtiendo en nuestra mayor fuente de información sobre los asentamientos neolíticos en las zonas que nos ocupan.

La Meseta Sur, pese a tener enormes posibilidades en este aspecto, no ha gozado de una labor sistemática de prospección y excavación como hubiera sido de desear, pues las autonomías que se ocupan del Patrimonio en estas áreas, hace algunos años que no conceden proyectos de investigación sino que centran sus esfuerzos en la arqueología de gestión. Nuestro equipo ha intentado adaptarse a este tipo de financiación que, desde luego tiene sus problemas de cara al desarrollo de una investigación cuyos resultados nos cuesta años conseguir, pero que a la larga puede ofrecer una perspectiva del poblamiento megalítico de la cuenca interior del Tajo (Bueno Ramírez et al. 2000a: 446).

En esa dinámica, nuestros trabajos en Toledo se han centrado en los monumentos de Azután, La Estrella (Bueno Ramírez 1990 y 1991; Bueno Ramírez y de Balbín Behrmann 1996 y 1998) y Navalcán (Bueno Ramírez et al. 1999), en relación a los distintos avisos emitidos por instituciones o personas de la zona. Este caso es el mismo para los yacimientos del término de Huecas (Bueno Ramírez et al. 1999, 2000a y b), a los que acudimos por el peligro que corrían en relación con la construcción de un pantano.

La presencia de un túmulo sin estructura megalítica en término de Huecas, relativamente próximo al dolmen de Azután y con fechas C14 muy semejantes, nos lleva a proponer una reflexión en estas páginas acerca de las relaciones y diferencias entre los túmulos con y sin estructura interior en una primer fase del megalitismo, que nos parece interesan- te de cara a valorar situaciones semejantes en otros sectores de la Meseta con materiales muy parecidos, algunos tan característicos como las espátulas tipo el Miradero (Delibes et al. 1987), localizadas en el túmulo del Castillejo.

Los indicios de habitat en el túmulo del dolmen de Azután, en el de Navalcán y, con más amplitud, en el túmulo del Castillejo, vienen a reiterar la contigüidad habitat/enterramiento tan común en las excavaciones de los últimos años, tanto en la Meseta Norte (Delibes y Zapatero 1996; Rojo et al. 2002), como en algunas zonas megalíticas del Oeste (Bueno Ramírez 1988 y 2000; Gonçalves y Sousa 2000; Senna-Martínez 1996).

El yacimiento del Castillejo se ubica en un territorio de enorme riqueza arqueológica en el que también nos encontramos excavando una necrópolis con cuevas artificiales (Bueno Ramírez et al. 1999 y 2000), lo que nos permitirá proponer hipótesis sobre la relación entre el poblamiento neolítico y calcolítico de la zona. Si a ello añadimos la presencia de materiales de Neolítico Final y Calcolítico en los dólmenes toledanos, estamos en condiciones de argumentar una secuencia larga para los megalitos de la zona.

La consideración de un neolítico pre-megalítico en el interior ha ido tomando consistencia en los últimos años y trabajos recientes aportan interesantes novedades al respecto (Bueno Ramírez et al. 1995 y e. p.; Delibes y Zapatero 1996; Díaz del Río 2000; Rojo y Estremera 2000).

Las supuestas ausencias eran sólo auténticos desconocimientos. Nos queda ahora mucho trabajo por desarrollar en este campo, pero los yacimientos que conocemos apuntan a la existencia de una base demográfica importante en las culturas del interior peninsular. El megalitismo se implanta en estos sectores en fechas semejantes a las sepulturas en piedra de la fachada atlántica peninsular (Bueno Ramírez 1991: 112), situándose en un Neolítico formado, Medio y Final en las terminologías al uso (Fig. 1).

Nuestro objetivo, el de la comparación de dólmenes y túmulos sin estructura megalítica, se va a establecer a partir de la consideración de los yacimientos funerarios en su vertiente de yacimientos de habitación, utilizando para ello la metodología al uso con una propuesta sobre las posibilidades económicas de los yacimientos valorados, de la comparación de los materiales asociados a los enterramientos, de la selección de sexos y edades que podemos conocer tanto en el dolmen de Azután

T. P., 59, n. ${ }^{\circ}$ 2, 2002 


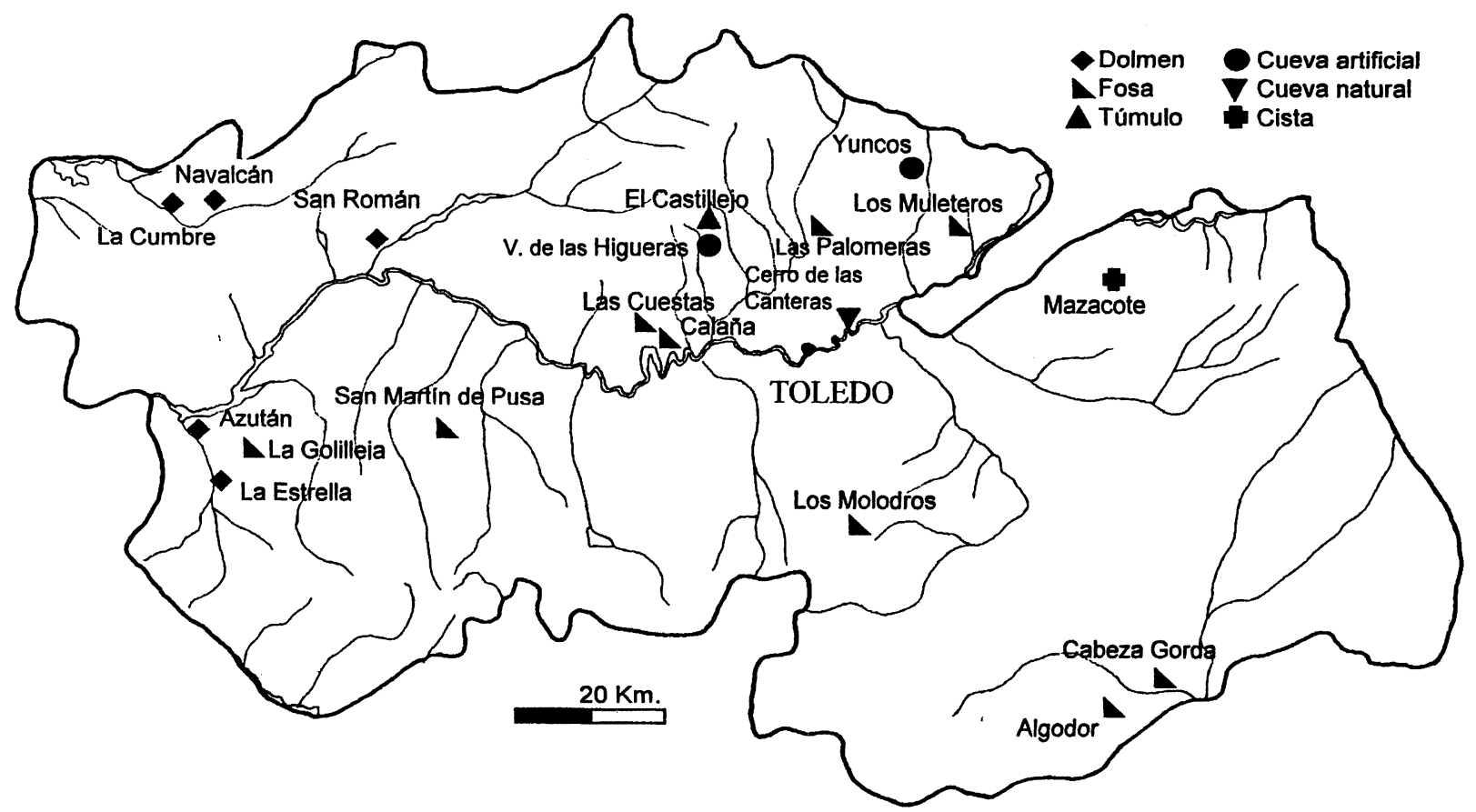

Fig. 1. Áreas funerarias neolíticas y calcolíticas de la provincia de Toledo.

como en el túmulo del Castillejo y de la constatación de los usos largos de ambos tipos de panteón, además del análisis de las posibles secuencias hábitat/enterramiento.

Así procedemos a asentar una premisa para la valoración del megalitismo occidental que, hoy por hoy, resulta ineludible: la asociación inmediata de áreas de habitación y áreas funerarias, constituyéndose ambas en el espacio transitado.

Con este punto de partida, el de la profunda imbricación entre el espacio de la vida y el de la muerte (Bueno Ramírez 2000), nuestras consideraciones sobre el territorio de los megalitos, son tambien reflexiones sobre la situación de las poblaciones neolíticas interiores y sus relaciones con elementos culturales, tanto del Oeste como del Sur y del Norte de la Península, diseñando una riqueza cultural y demográfica hasta ahora insospechada.

\section{LAS ULTIMAS CAMPAÑAS DE EXCAVACIÓN EN EL DOLMEN DE AZUTÁN Y EN EL TÚMULO DEL CASTILLEJO}

Como decíamos arriba, centraremos nuestra reflexión en los dos yacimientos toledanos por representar versiones aparentemente diferenciadas de los sistemas funerarios megalíticos, ambos con fechas antiguas, y con materiales, restos humanos, faunísticos y vegetales, que nos permiten proponer una hipótesis sobre los sistemas de aprovechamiento del territorio en esta región de la cuenca interior del Tajo.

Nuestras excavaciones en el dolmen de Azután fueron objeto de publicación en los años 90 (Bueno Ramírez 1990 y 1991), pero el interés del monumento, la conflictiva diferencia de fechas del osario colectivo y la evidencia de un ajuar antiguo de enorme interés para las propuestas de secuencia del megalitismo en la Submeseta Sur, nos llevaron a realizar una nueva intervención en 1991 dirigida a levantar el resto de losa de cobertura que tapaba una nimia parte de depósitos y a realizar otro corte en profundidad en el túmulo, con objeto de valorar los indicios ya detectados en las campañas anteriores en los denominados sectores 1, 2 y 3 (Bueno Ramírez 1991) (Lam. I).

Los resultados de esta campaña serán estudiados pormenorizadamente en un trabajo próximo en el que además incluiremos los calcos completos de la decoración del monumento, pero en lo que ahora nos interesa, sirvieron para ratificar la antigüedad del depósito de la cámara y para documentar fehacientemente la existencia de un nivel de ocupación en el túmulo con restos cerámicos y faunísticos (Fig. 2). 


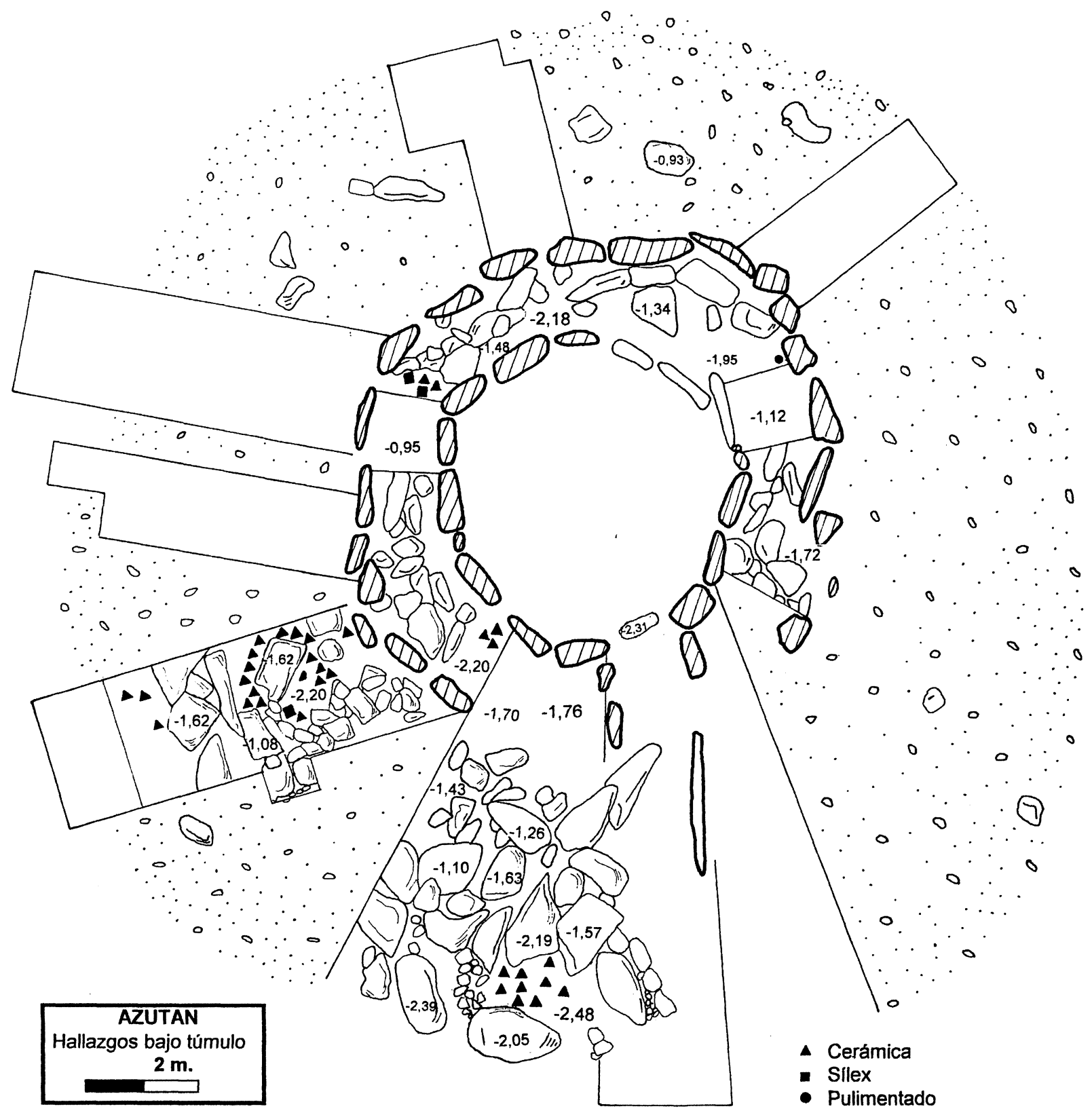

Fig. 2. Ubicación de los materiales de habitación bajo el túmulo del dolmen de Azután: sectores 1, 2 y 3 GTS campaña 91 y CT4, campaña 2000.

En la cámara, el resto de depósito que quedaba se ubicaba bajo una parte de la losa de cobertura, indicio que además nos sirve para proponer la cobertura adintelada de este espacio, como hemos justificado en otro lugar (Bueno Ramírez et al. 1999: 88). En él volvimos a documentar una acumulación ósea importante muy afectada por la caída de la piedra y por el sistema de remoción de los restos (Bueno Ramírez 1991: 106). La fragmenta- ción de los mismos, muy evidente, sólo nos permitió obtener muestra de uno de los individuos enterrados en el último momento del depósito. Concretamente, el análisis se realizó sobre una mandíbula de individuo juvenil y dió como resultado $4620 \pm$ 40 BP (Beta-145277).

A este momento se asocian los pocos fragmentos cerámicos lisos documentados (Fig. 3) y una espátula realizada sobre costilla de bóvido como 


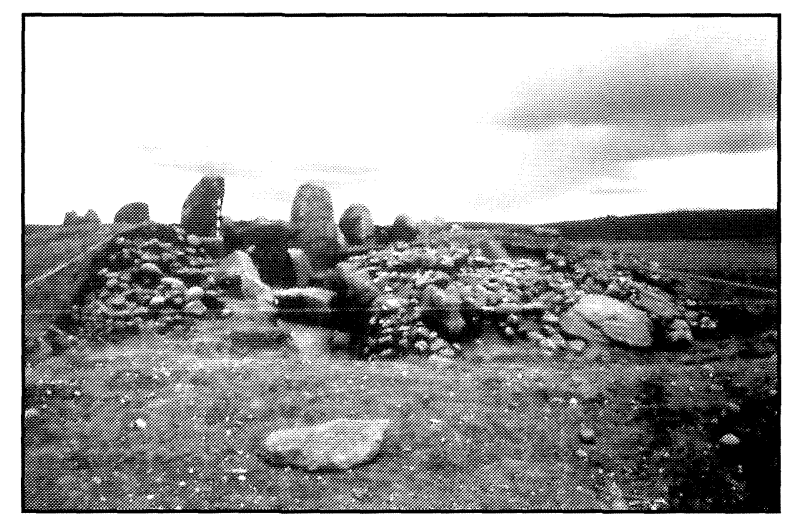

Lam. I. Vista general del dolmen de Azután. En primer plano cortes de la zona Este del túmulo. Campaña 1991. Foto R. de Balbín.

otras del mismo tipo documentadas en yacimientos meseteños (Delibes y Zapatero 1996: fig. 2.2), identificada por B. Sánchez.
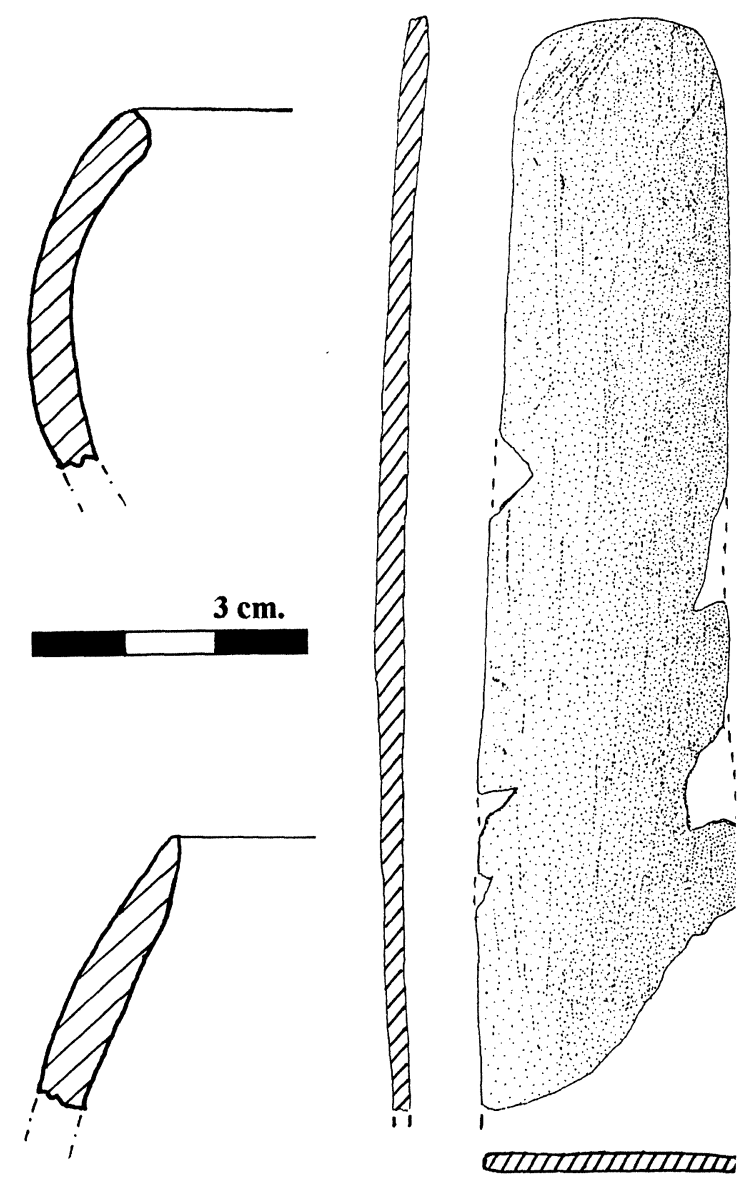

Fig. 3. Cerámica y espátula asociadas a la fecha $4620 \pm 40$ BP (Beta 145277). Campaña 1991
En la base de la cámara, tanto los restos humanos como los ajuares son menos abundantes. Los únicos materiales son un pequeño fragmento de borde con perforaciones verticales, en la línea de algunas producciones del neolítico andaluz, que encaja con la cerámica decorada que documentamos en la primera campaña (Bueno Ramírez 1991: fig. 35) y de la que incluimos un nuevo dibujo, además de microlitos, laminitas y una cuenta de collar de caliza con restos de color rojo (Fig. 4).

La primera utilización del dolmen de Azután incluía abundantes microlitos geométricos, algunos de ellos tipométricamente antiguos (Bueno Ramírez 1991: 100), laminitas, cerámicas con borde de surco, algunas impresas y cerámica a la almagra, además de un punzón de hueso y la mencionada cuenta de collar.

Otras evidencias de ocupación son más recientes, como indican las fechas del V milenio BP, aunque en ningún caso documentamos puntas de retoque bifacial. La fecha obtenida para la ocupación final de la cámara en la primera campaña y la que ahora mencionamos, sitúan estas últimas deposiciones de la cámara en el Neolítico Final haciendo patente la continuidad del uso del monumento, al igual que tenemos constatado en otros dólmenes de la fachada occidental (Bueno Ramírez 1991: 112).

La presencia de campaniforme marítimo en el sector externo del corredor asociado a restos humanos, aboga por el uso del megalito hasta el IV milenio BP, del mismo modo que sucede en otros monumentos toledanos, incluyendo en ellos el túmulo del Castillejo (Bueno Ramírez et al. 1999 y 2000).

Si la ratificación de la ocupación antigua del dolmen de Azután parecía necesaria, la documentación del posible nivel habitacional que tímidamente habíamos apuntado en la publicación anterior, se hacía imprescindible ante la acumulación de evidencias de ese tenor en otras áreas megalíticas, especialmente en la submeseta Norte.

Para ello, en la campaña del 91 realizamos un corte radial en el túmulo, junto a los ortostatos del sector Sur del corredor. Tras el levantamiento de la masa pétrea compuesta por cantos de cuarcita y contenciones de granito, alcanzamos un nivel de tierra oscura con abundantes restos cerámicos, esquirlas líticas y restos faunísticos, que unidos a los ya descritos en los sectores 1,2 y 3 de la primera campaña, conforman un nivel infratumular de ocupación. Las características tipológicas de los materiales no resultan muy alejadas de las constatadas en el primer momento de ocupación de la cámara, 

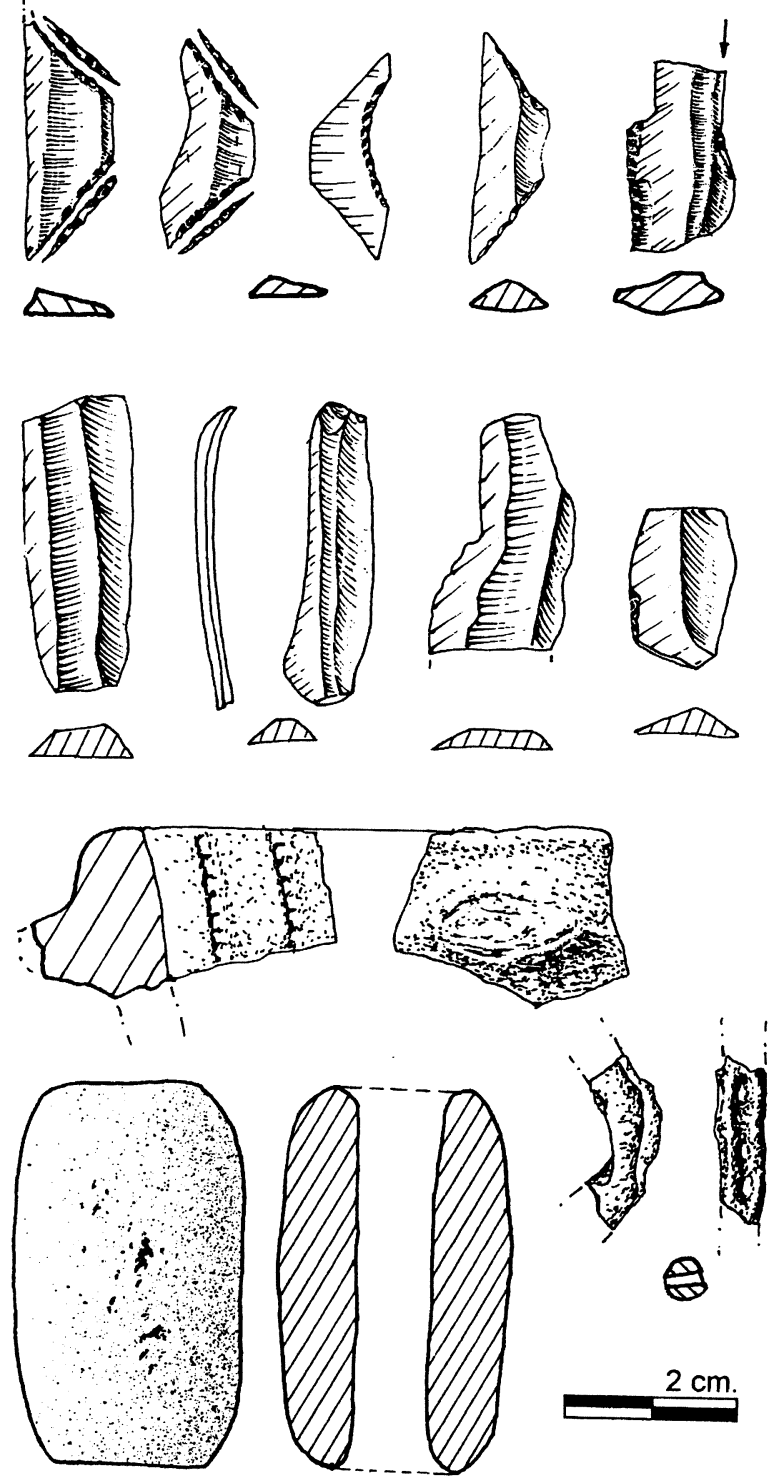

Fig. 4. Cerámica decorada, microlitos, laminitas y cuenta de collar del nivel antiguo de la cámara del dolmen de Azután.

lo que abogaría por una cercanía relativa entre ambas circunstancias: habitación y enterramiento, corroborando propuestas similares en la meseta Norte (Delibes y Zapatero 1996: 340).

La apertura de otros dos cortes en la campaña del 2001, con motivo de la realización de las bases para el proyecto de reconstrucción del monumento, nos permitó verificar la situacion del habitat bajo túmulo, en esta ocasión con la ventaja de una fecha C14, obtenida de uno de los postes de la cabaña documentada en CT4. La fecha es $5250 \pm 40$ BP (Beta157731). Los materiales: bordes con surco, cerámi- ca impresa e incisa y molinos apuntan de nuevo a la equiparación con los ajuares más antiguos del monumento.

El túmulo del Castillejo ha sido objeto de dos campañas. La primera de ellas fué muy sucinta pero nos permitió dar a conocer la presencia de un yacimientos funerario sin estructura megalítica con dos agrupaciones mortuorias, al que se asociaban otro tipo de estructuras de posible carácter habitacional (Bueno Ramírez et al. 1999; 2000 a).

La campaña realizada en 1999 verificó la presencia de cabañas en las proximidades del área funeraria, además de circunscribir las deposiciones a dos momentos, uno más antiguo y otro más reciente al que han de asociarse los vestigios de cobre y cerámica campaniforme. Aún estamos pendientes de realizar otra campaña en el monumento pues no hemos alcanzado la base en la totalidad del mismo.

El primer grupo de enterramientos se sitúa en la parte más alta del cerrito calizo que se denomina en el lugar "El Castillejo". Los depósitos dibujan una agrupación de tendencia circular en torno a los $3 \mathrm{~m}$ de diámetro que alberga más de una docena de cadáveres.

La sistemática asociación de cráneos a huesos largos de brazos, nos permite reconstruir la posición de los cadáveres como encogida y su asociación ocasional a piedras de tamaño medio, nos lleva a sugerir ciertas divisiones internas del depósito que quizá puedan conectarse con una mayor proximidad parental entre los individuos que dichas piedras delimitan.

Los ajuares son muy reiterativos: microlitos, láminas de pequeño tamaño, punzones de hueso, cerámica de bordes con surco, alguna decorada y dos espátulas que encajan con las formas denominadas San Martin-el Miradero (Delibes et al. 1987) en la Meseta Norte. Para este nivel disponemos de una fecha C14, $5710 \pm 150 \mathrm{BP}$ (Beta 132917) (Bueno Ramírez et al. 1999: 149), muy próxima a la fecha más antigua de Azután (Fig. 5).

Con orientación E/SE se sitúa un círculo de en torno a $1 \mathrm{~m}$. de diámetro delimitado por piedras medianas que contiene una deposición de adulto joven sobre la que se ha hecho una muestra C14, y otra de un individuo infantil. La primera, un joven de 18 años según la identificación de Etxeberría y Herrasti, proporcionó la fecha: $3810 \pm 70 \mathrm{BP}$ (Beta145274), muy similar a las obtenidas en la cercana necrópolis de cuevas artificiales de Valle de las Higueras (Bueno Ramírez et al. 2000 a y b).

T. P., 59, n. ${ }^{\circ} 2,2002$ 


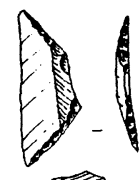

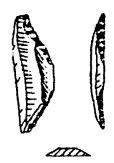<smiles>c1ccc(C23CC4CC(C2)C(C4)C3)cc1</smiles>

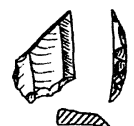
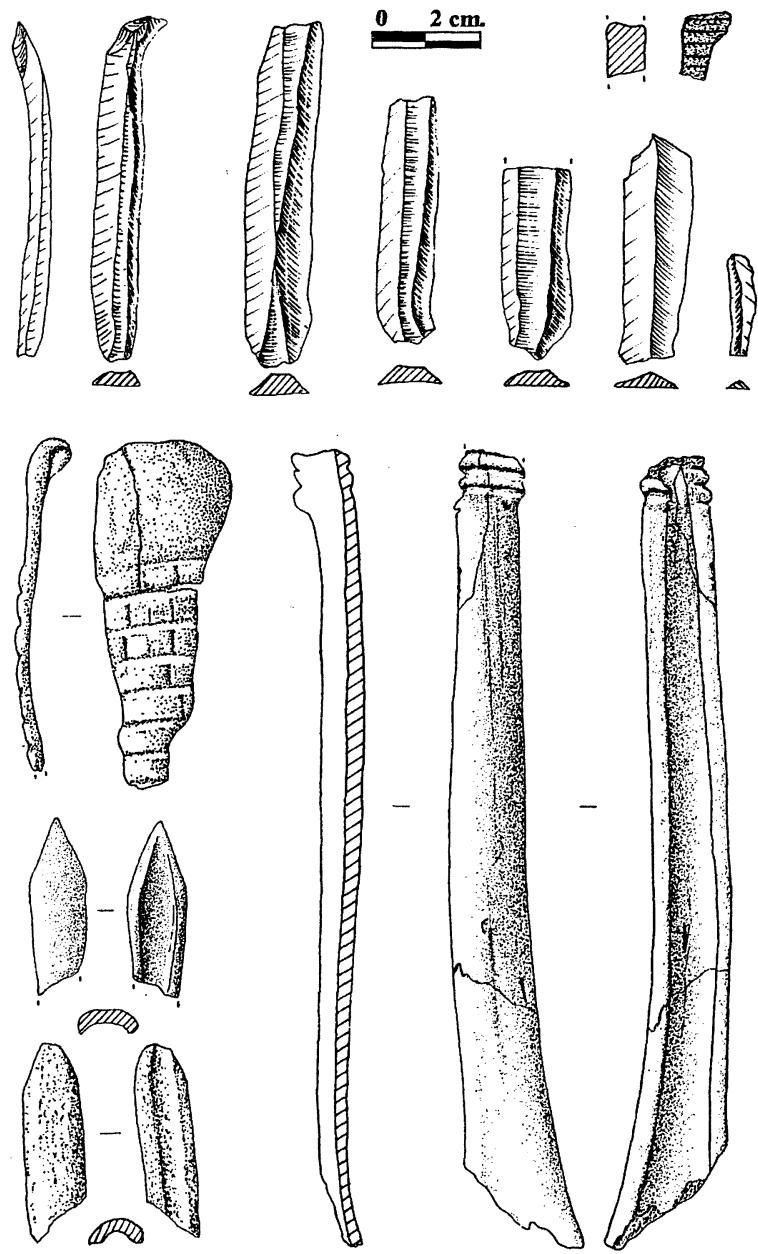

Fig. 5. Castillejo: Ajuares asociados al depósito neolítico. Microlitos, laminitas, espátulas decoradas.

La excavación del 98 había proporcionado pocos elementos de ajuar: fragmentos de pulimentados, alguna lámina y fragmentos de cerámica incisa. La reconstrucción que hemos hecho de la dispersión del material en la zona superior del túmulo nos ha permitido verificar que algunos fragmentos de esta zona pegaban con los decorados del enterramiento que describimos, conformándose como evidencias campaniformes. Por ello consideramos lógico adscribir el punzón de cobre que apareció prácticamente en superficie (Bueno Ramírez et al. 1999: fig. 4) a estos enterramientos. A ello se suma el uso de barro en la base de la estructura, sistema que tenemos constatado en las sepulturas calcolíticas y de la Edad del Bronce de la ya citada necrópolis de Valle de las Higueras, situada en un cerro próximo.

El pequeño círculo que nos ocupa, que en la campaña del 98 describimos como nivel II para separarlo del anterior, con los datos de que hoy disponemos, puede relacionarse con estructuras semejantes detectadas en la provincia de Avila. El yacimiento de Aldeagordillo con una fecha $\mathrm{C} 14$ similar a la nuestra (Fabián 1992), constituye una referencia muy próxima.

Las dos agrupaciones descritas sugieren un uso del espacio muy similar al de los megalitos, si bien hasta el momento no hemos documentado ninguna evidencia que permita plantear la existencia de estructura alguna. El círculo mayor, de unos tres metros de diámetro, alberga el depósito más antiguo, a modo de cámara funeraria, reproduciendo incluso medidas comunes en este tipo de espacios. El círculo que contiene los depósitos campaniformes se ubica al Sureste, una orientación corriente en los corredores dolménicos, en algunos de los cuales se documentan enterramientos adscribibles a esta cultura. Sin ir más lejos, en el mismo dolmen de Azután.

A la cabaña 1 del túmulo del Castillejo que describíamos en el trabajo anterior (Bueno Ramírez et al. 1999: 153) datada por C14 en $4930 \pm 40 \mathrm{BP}$ (Beta-132915), se suman las detectadas en los cortes 3 y 4 que avalan la amplitud del área de habitación. Los materiales de éstas: cerámicas lisas, a la almagra, con bordes de surco, molinos y microlitos, abogan por una ocupación neolítica, a tenor de las fechas, posterior a las primeras deposiciones, reflejando un fenómeno similar al del túmulo de Rebolledo, en Sedano (Delibes y Rojo 1997: 405-406). Sin olvidar que reiteran un tipo de material que parece tener un largo recorrido cronológico en la zona que nos ocupa. No obstante, aún tenemos que excavar debajo de los enterramientos pues sospechamos la presencia de un nivel de ocupación más antiguo (Lam. II y III).

Los estudios de F. Etxeberría y L. Herrasti sobre los restos humanos del Castillejo y los de A. Gonzalez y M. Campo sobre las nuevas evidencias de Azután, sumadas a las ya analizadas por V. Galera, plantean interesantes reflexiones sobre los depósitos funerarios.

La primera diferencia evidente es la amalgama ósea de Azután donde los restos debieron ser lite- 


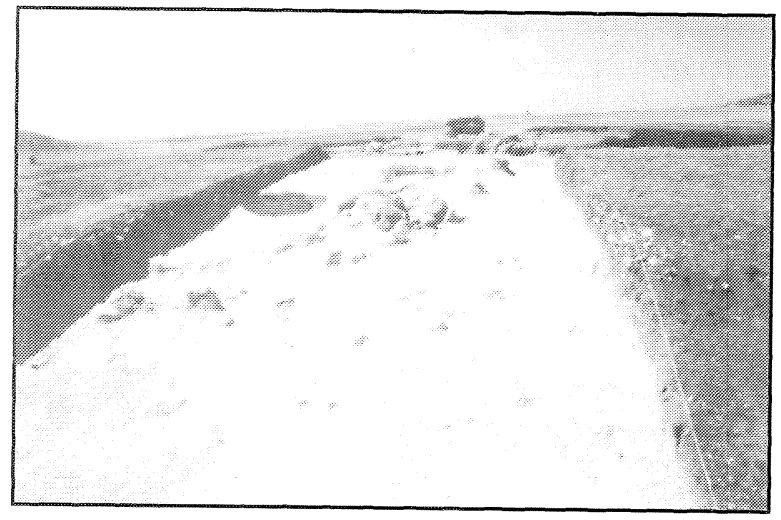

Lam. II. Cabaña y silos del corte 2. Foto R. de Balbín.

ralmente empujados, mientras que los restos del Castillejo, sea mejor o peor su conservación, están colocados de lado, encogidos y, en cierto sentido, ordenados. Esta diferencia en el tratamiento de los cadáveres se ha observado en yacimientos semejantes de la Meseta Norte (Etxeberría y Delibes 2002: 43)

La representatividad de sexos y edades es relativa, pues nos movemos en una cifra estadística muy pequeña, pero cuando menos es interesante de cara a lo que sabemos de este tema en la Meseta Norte (Delibes 1995).

Ya con nuestras excavaciones de los 80 llamaba la atención la presencia de individuos infantiles (Galera 1991: 56) en Azután que ahora estamos en condiciones de ratificar con las interesantes aportaciones de A. Gonzalez y M. Campo. Infantiles y juveniles, entendiendo éstos como individuos hasta 14 años, alcanzan una proporción significativa, lo que coincide con los datos que tenemos del Castillejo, tanto en el caso de su ocupación antigua, como en el de la más reciente.

La presencia de este espectro de edades en los enterramientos megalíticos peninsulares no es un hecho aislado, pero sí poco documentado hasta el momento entre otras razones por la escasez de materia ósea conservada, pero es relativamente común en los megalitos de la fachada atlántica (Briard 1995: 44) o en otros cementerios europeos como es el caso de los utilizados por los neolíticos danubianos (Jeunesse 1997: 98), a los que curiosamente se asocian huesos largos pulidos con apariencia antropomorfa que recuerdan a nuestras espátulas San Martin-El Miradero.

Por último hay que comentar la presencia de un tipo senil que V. Galera (1991: 55) calculó como de

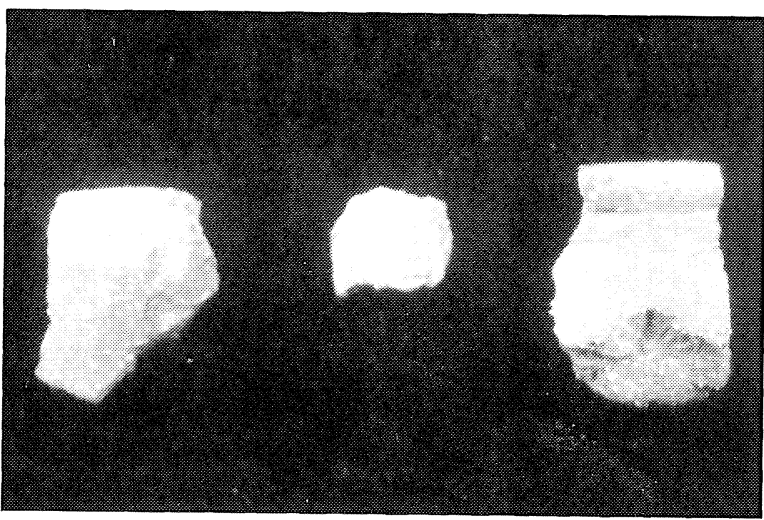

Lam. III. Materiales cerámicos del habitat del Castillejo. Cabaña 2. Foto R. de Balbín.

60 años, espectro de edades muy poco representado en restos antiguos. Este tipo de individuos con dificultades para su subsistencia diaria son los que vienen planteando desde su descubrimiento entre restos paleolíticos, la existencia de una solidaridad en el grupo y un más que posible respeto a las personas de edad o con dificultades físicas que les permitieron sobrevivir.

\section{ECONOMÍA Y MEDIO AMBIENTE EN LOS YACIMIENTOS MEGALÍTICOS DE TOLEDO}

Los datos que podemos barajar en este sentido derivan de la propia situación de los yacimientos y de las evidencias, tanto paleofaunísticas como paleobotánicas. Todas ellas apuntan una serie de indicios de enorme interés para reconstruir las sociedades neolíticas de la región como grupos con asentamientos junto a sus megalitos y un enraizamiento en el lugar demostrado por los restos habitacionales sellados por sus sepulturas.

El hecho de la situación de los monumentos junto a vías de paso tradicionales (Bueno Ramírez 1991: 13), ofrece un argumento más para hablar de pastores con una trashumancia corta, que utilizan como referente los mismos lugares: sus áreas funerarias que son además los lugares de vivienda. En otro lugar (Bueno Ramírez et al. 1999: 127), hemos señalado que esta situación junto a vías de paso favorece tambien el control del intercambio de materias primas, cuestión que se revaloriza al observar la presencia de algunos objetos como las espátulas tipo El Miradero, que si no necesariamente importadas, sí dejan ver el conocimiento de

T. P., 59, n. ${ }^{\circ} 2,2002$ 
estos objetos tan característicos de los megalitos de la Meseta Norte, la Rioja y el País Vasco, en la Meseta Sur. Así estos caminos, concretamente la Cañada Real Leonesa que atraviesa el país de Norte a Sur, fueron tambien el conducto utilizado para establecer intercambios que explican la presencia de estos "productos" tanto en el Norte como en el Sur de la Península. Probablemente en esa dinámica de interrelaciones Norte/Sur ocupan un papel los elementos procedentes del Sureste que alcanzan el interior de la Península (Martínez Navarrete 1984) y que tantas veces se han barajado para explicar las culturas neolíticas y calcolíticas del País Vasco (Apellániz 1973).

Por tanto, una primera visión de los territorios de nuestras sociedades megalíticas propone una amplitud de relaciones dentro de la Península, que diseña culturas dinámicas y no conjuntos cerrados y marginales. Si los nexos con el Norte pueden establecerse como hemos dicho, no es menos cierto que tenemos evidencias de relaciones con el Oeste que se dejan ver en la disposición de las arquitecturas megalíticas (Bueno Ramírez 1991), en las características de las decoraciones (Bueno Ramírez y de Balbín Behrmann 1996), en algunos tipos cerámicos y, en las deposiciones colectivas sin estructura megalítica cuyo referente más claro son los enterramientos documentados en los concheros de la desembocadura del Tajo.

A ello se suman determinadas características en las cerámicas decoradas que apuntan al neolítico andaluz (Fernández-Posse 1980), sin olvidar su presencia en áreas del Oeste (Diniz 1996).

Este breve diseño de relaciones conecta mejor con la posición geográfica de la Meseta, pues la supuesta inexistencia de población en la zona central obligaba a una circulación perimetral de culturas y gentes que los datos iban haciendo aparecer cada vez más forzada. Los sectores interiores del Tajo y del Duero guardan una posición inmejorable para conectar las particularidades de cada uno de los grupos neolíticos y calcolíticos que se desarrollan en los cuatro puntos cardinales de la Península.

Centrándonos en las posibilidades concretas del territorio próximo a los yacimientos megalíticos que ahora nos ocupan, integraremos éstas en el círculo de $5 \mathrm{Km}$. tomado como referencia mínima en los estudios al uso (Higgs y Vita Finzi1972). La finalidad funeraria de nuestros yacimientos no obsta a la consideración de los mismos como yacimientos de habitación, ya sea antes de construir el megalito, ya contemporáneamente al depósito fu-

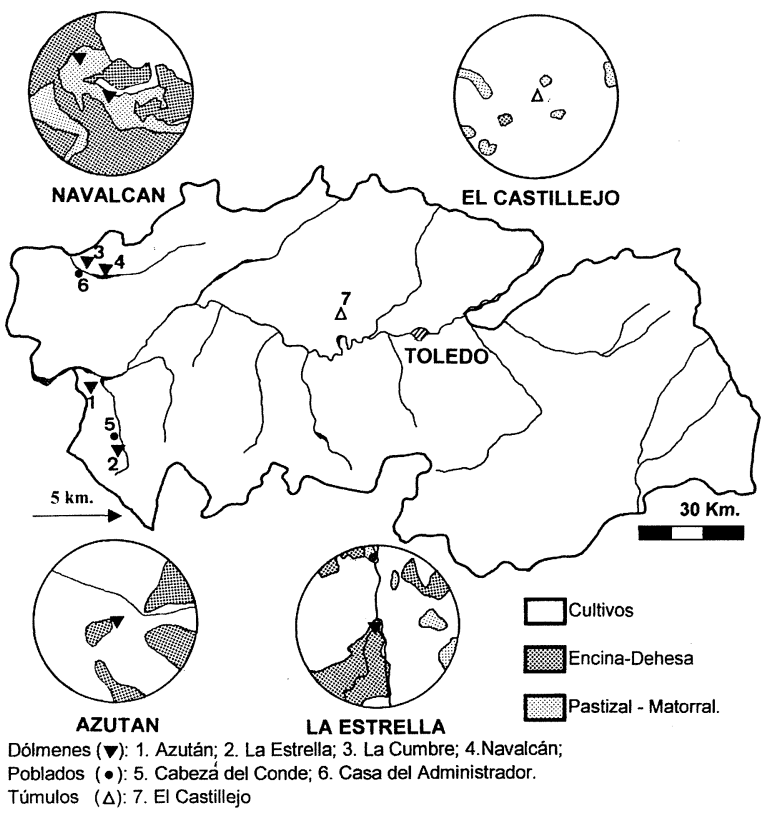

Fig. 6. Áreas de explotación económica de los dólmenes excavados en la provincia de Toledo y del túmulo del Castillejo.

nerario, por lo que éstos serán tratados bajo esa perspectiva (Fig. 6).

En lo que hoy sabemos, los megalitos se concentran en el sector Oeste de la provincia en una agrupación que suponemos ficticia, dado que tenemos suficientes evidencias más al interior del Tajo, en Madrid y Guadalajara, para sospechar que una prospección intensiva propondría una situación más amplia de los megalitos toledanos. A ello ha de sumarse la posibilidad de otro tipo de estructuras con enterramientos colectivos, como demuestra el túmulo del Castillejo en un sector más interior de la provincia.

Los territorios de dólmenes y túmulo, globalmente considerados, apuntan a una dedicación mixta, si bien las actuales explotaciones agrícolas de regadío junto al Castillejo, disfrazan un tanto la realidad pasada. La dedicación se concreta en cada uno de los monumentos que se explicitan, tanto por su posición altimétrica, como por su relación con sectores de sierra o pie de sierra, sus posibilidades de acceso a tierras de productividad agrícola, su asociación a cursos de agua y a vías de paso, sin dejar de lado otro tipo de materias primas como el cobre que tambien posee ejemplos de interés en la región (Montero et al. 1990).

Disponemos de análisis de fauna en el dolmen de Azután y en el túmulo del Castillejo, así como de 

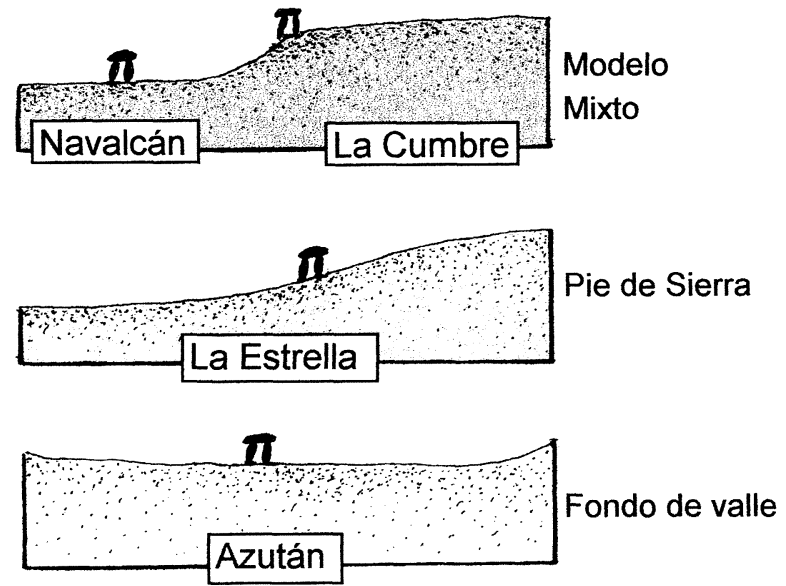

Fig. 7. Modelo de situación de los yacimientos funerarios y de habitación del primer horizonte megalítico de la provincia de Toledo.

análisis polínicos en los mismos yacimientos. A ello podemos añadir la analítica realizada sobre molinos procedentes de los dos ejemplos mencionados. El resto de los monumentos no nos han dado opción a la realización de este tipo de analíticas, pero una visión sobre sus posibilidades de explotación del territorio próximo apunta a una serie de opciones comparables a las que propondremos para el Castillejo y Azután. La permanencia recurrente en un mismo territorio viene avalada por la presencia de materiales campaniformes en todos los megalitos toledanos, lo que nos sirve para argumentar un modelo continuado de explotación del territorio que tiene vigencia en un Calcolítico avanzado.

Naturalmente, no podemos negar la existencia de otros modelos de asentamiento en el territorio pero los yacimientos que aquí valoramos plantean que el aprovechamiento mixto, con un peso específico de la dedicación ganadera, no varió sustantivamente en algunos núcleos de población que, en todo caso, demuestran una intensificación progresiva como propone la amplitud de la necrópolis de Valle de las Higueras (Bueno Ramírez et al. 2000a y b).

Los dólmenes de La Cumbre (Carrobles et al. 1994) y La Estrella se sitúan en terrenos de pie de sierra en los que la dehesa mediterránea continúa poseyendo un importante papel en el entramado ganadero que sustenta el mayor peso de su economía.

La evidencia de poblamiento al aire libre en la proximidad de los monumentos (Bueno Ramírez et al. 1999: 123) e, incluso de poblados con apariencia más estable como el que se sitúa junto al dolmen de la Estrella (Carrobles y Méndez 1991: 8), muy probablemente enraizado en el Neolítico Final, como sucede en próximos sectores de la zona del Tajo (Bueno Ramírez et al. 2000), plantea las áreas funerarias como parte de un territorio en el que los habitats ocupan una situación muy próxima, si no claramente inmediata.

Podríamos, pues, establecer tres modelos preferentes en la ubicación de nuestros megalitos: fondo de valle, pie de sierra y un modelo mixto que incluye las dos opciones en un mismo territorio (Fig. 8).

Azután, Navalcán y el Castillejo muestran la misma tendencia a situarse en fondos de valle, sobre la primera terraza del río, situación muy similar a la de algunos monumentos salmantinos (Delibes y Santonja 1986) que indica la posibilidad de explotaciones de carácter agrícola. Los análisis polínicos de Azután y lo que puede deducirse de la flora acompañante en el caso del Castillejo reconstruyen el paisaje mayoritario en estos territorios como dehesas aclaradas para pastos y para obtener aprovechamientos agrícolas (Fig. 7).

Los análisis realizados por J. A. López Sáez y P. López García en el dolmen de Azután son muy explícitos. Las muestras tomadas bajo el túmulo del monumento indican que el paisaje predominante en el momento anterior a la construcción era una dehesa con mayor humedad ambiental que la actual y un importante progreso de la fresneda que se corresponde bien con un clima mediterráneo húmedo.

La antropización del medio anterior a la implantación del dolmen, se hace evidente en el nivel inicial del relleno tumular, que si bien no presenta material arqueológico refleja un paisaje de encinares abiertos con zonas de pastizal y una importante presencia de Olea europea que interpretan como producto de una densa magma de acebuche en el lugar.

El tema del cultivo del olivo ha adquirido en los últimos años carácter propio pues las evidencias de éste en gran cantidad de yacimientos apuntan a su uso doméstico, mientras que las pruebas fehacientes de dicho cultivo (aumento del tamaño de los frutos), se muestran realmente esquivas, por lo que la cuestión se ha resuelto a favor de un cierto consenso sobre su cultivo seguro durante la Edad del Bronce. Aún así, Buxó (1997: 12) plantea la posibilidad de una intervención antigua en el olivo silvestre a raíz de los datos del yacimiento de Can Tintorer. Los trabajos sobre muestras antracológicas de yacimientos neolíticos del Sureste francés 
realizados por Tenol $(2000,2001)$ confirman la intervención en el acebuche .

Los escasos datos del nivel bajo túmulo de Azután no son nada definitivos, pero se unen a los ya expresados para generar una expectativa convincente acerca del control del acebuche en el contexto de los biotopos de dehesa del Sur de Europa. De este modo, la dehesa y todo su entorno georístico se dibujaría como un manejo antiguo en relación con los orígenes de los sistemas de producción.

El nivel de habitación documentado en el túmulo refleja el predominio de encinares abiertos con algún enebro y zonas de pastizal ahora acompañadas de Cerealia, interesante dato que nos permite, por primera vez en el centro de la Península, constatar la existencia de una economía mixta con cultivo de cereal en un estilo muy semejante a la detectada en otros sectores megalíticos peninsulares (Aira et al. 1989).

La presencia de harina de bellota en los molinos de Azután y el Castillejo, propone un aprovechamiento intensivo del medio natural en el que la dehesa, como sistema de cultivo, alcanza una dimensión estimable en el conjunto de los recursos económicos. Los interesantes resultados del estudio de paleodieta de Azután que habremos de contrastar con los que se realizen en el Castillejo, confirman los datos que acabamos de exponer. Las reflexiones que propone este estudio serán objeto de otro trabajo en colaboración con G. Trancho y su equipo.

A las evidencias agrícolas se suma la detección de Ovis en las cabañas bajo túmulo del dolmen de Azután, además de bóvidos y algún équido que B. Sanchez ha identificado como asno. Ovis y Bos, tambien aparecen asociados a los depósitos funerarios de la cámara.

En el Castillejo, las espatúlas tipo San Martín-El Miradero se han realizado sobre tibias de ovicápridos, reiterando la presencia de estos animales en fechas similares a las del depósito antiguo de Azután.

El territorio que ocupa el Castillejo está plagado de asentamientos próximos, muchos de los cuales aún tenemos en estudio. Ya especificamos la situación de la necrópolis de Valle de las Higueras (Bueno Ramírez et al. 2000) y la del habitat anexo al enterramiento. A ello se suman evidencias en casi todos los cerretes de alrededor, algunas de ellas con cerámicas impresas que, como decíamos, aún tenemos en estudio.

El Castillejo se ubica en fondo de valle, pero en una situación destacada en el entorno por la propia altura del túmulo y por levantarse a la orilla de una importante laguna, al otro lado de la cual se desarrolló un enorme poblado ocupado durante el Neolítico Final y el Calcolítico, a tenor de las evidencias de superficie. De ser así, los muertos y el habitat del Castillejo serían la implantación más antigua del conjunto humano que habitó el valle durante más de tres milenios de modo ininterrumpido.

Los análisis polínicos realizados por J. A. López Sáez y P. López García indican la insignificante presencia de pólenes en las tierras asociadas a los enterramientos de VI milenio BP. En las tierras procedentes del área de habitación, especialmente en la cabaña de mayor tamaño detectada en el Corte 2 (Bueno Ramírez et al. 1999: 153), se advierte un paisaje muy abierto con encinas que podría responder a actividades pastoriles por la presencia de Plantago lanćeolata y Urtica dioica. La identificación de ovicápridos como materia prima de las espátulas del Castillejo ratifica la presencia antigua de Ovis en la zona interior, como ya hemos señalado.

Entre los árboles destaca el nogal y el pino. Esta última especie no se corresponde con una presencia natural por lo que quizá podría explicarse como parte de la madera quemada, y por tanto, de aporte antrópico, en esta estructura de combustión.

Así la explotación del medio ejercida por los pobladores neolíticos del Castillejo parece fundamentalmente la ganadería.

El enterramiento anejo a las primeras deposiciones con fecha del IV milenio BP nos propone, además de la continuidad ideológica con los enterrados, la prosecución de los mismos sistemas de vida. Los análisis polínicos de este sector señalan la presencia de un paisaje abierto, muy deforestado, con pólenes de pino de carácter regional que probablemente procederían del Sistema Central. La presencia humana se advierte en el aporte orgánico de nutrientes y en la existencia de plantas Compuestas que denotan actividades varias, muy posiblemente relacionadas con el cultivo y la ganadería.

\section{HABITATS Y ENTERRAMIENTOS NEOLÍTICOS AL INTERIOR DE LA PENÍNSULA}

El trabajo desarrollado en los últimos años en la Meseta permite proponer una valoración de los primeros momentos del megalitismo interior en los que éste auna áreas de habitación con estructuras 


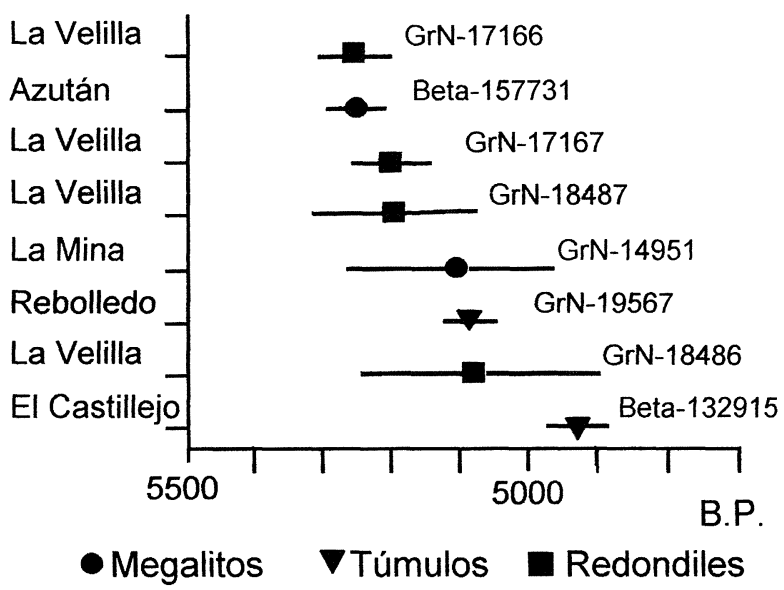

Fig. 8. Fechas BP del habitat bajo túmulo de las distintas estructuras funerarias megalíticas de la Meseta.

perecederas y áreas funerarias de distinto calado arquitectónico.

La abundancia de fechas C14 (Bueno Ramírez 1991; Cassen et al. 1993; Delibes y Rojo 1997; Kunst y Rojo 1999), se enriquece con las que ahora aportamos de la Meseta Sur para dibujar un panorama sobre el Neolítico Medio y Final de las zonas interiores de las cuencas del Tajo y del Duero, en el que sus manifestaciones no quedan nada alejadas cronológicamente de las situadas en los sectores occidentales de ambos ríos.

El estado de arrasamiento de las cabañas bajo túmulo del dolmen de Azután o del túmulo del Castillejo, coincide con la continuación del hábitat junto al monumento funerario, al igual que está constatado en los túmulos de la Mina y de Rebolledo (Delibes y Rojo 1997: 398). A estos ejemplos deberíamos sumar los de los Zumacales (Zapatero 1991: 59), San Martín de Valderaduey (Palomino y Rojo 1997: 250), Los Morcales (Rojo et al. 2002: 23), los yacimientos de Soria (Kunst y Rojo 1999) o, el más conocido de la Velilla (Delibes y Zapatero 1996). Algunos de los yacimientos mencionados disponen de fechas C14 que sitúan las cabañas bajo túmulo en el VI milenio BP, conformando un buen argumento para valorar la importancia del habitat al aire libre en la zona que nos ocupa durante una fase consolidada del Neolítico (Fig. 8).

La sospecha, cada vez más fundada, de que los monumentos funerarios son una evidencia a la que se asocian áreas de habitación, dibuja el megalitismo de las zonas interiores al que nos estamos refiriendo, como el dato más claro que hoy tenemos de asentamientos al aire libre en una región en la que los análisis de este tipo de yacimientos eran escasos. Así a los hábitats en cueva, supuestamente definidores de los grupos neolíticos interiores, habríamos de sumar un importante cúmulo de yacimientos al aire libre presididos por monumentos funerarios que conforman una idea del territorio y de la población neolítica interior absolutamente inédita.

La variedad de sus arquitecturas plantea un polimorfismo en el que deben conciliarse influencias externas de rápida implantación, que sólo se explican en ágiles sistemas de interacción de raíces antiguas, junto con interpretaciones locales. Entre las primeras situaríamos arquitecturas como Azután con reminiscencias beiranas y alentejanas, al igual que una gran parte del megalitismo interior, o los túmulos sin estructura megalítica como el del Castillejo, tan similares a los depósitos funerarios de algunos concheros de la cuenca occidental del Tajo. Entre los segundos, los redondiles y las arquitecturas de adobe de la Meseta Norte, probablemente interpretaciones locales de las cámaras megalíticas.

Si las fechas para el inicio de los asentamientos dolménicos bajo túmulo se sitúan sin mucha dificultad en el VI milenio BP, disponemos de datos más antiguos, del VII milenio BP, como los de la Velilla (Delibes y Zapatero 1996), los de los yacimientos sorianos (Kunst y Rojo 1999) o los del yacimiento cacereño de los Barruecos (Cerrillo et al. 2002) que nos permiten afirmar que los megalitos no constituyen la primera ocupación neolítica del territorio interior, sino que éstos se asientan en poblaciones anteriores que debieron poseer mayor calado demográfico del que los escasos datos de que ahora disponemos, señalan. Las fechas antiguas de la Velilla y de Ambrona, certifican la presencia de habitats al aire libre en momentos contemporáneos al desarrollo de yacimientos tan clásicos como Cova de l'Or.

Lo que sabemos acerca de las fechas de los megalitos interiores, sitúa sus inicios en el VI milenio $\mathrm{BP}$, en sus primeras centurias si tenemos en cuenta las de Valdemuriel (Delibes y Rojo 1987) y las antiguas de Azután y El Castillejo o en las centurias finales, si valoramos las arriba mencionadas de Velilla, Azután, o la Mina.

Sea como fuere, lo que está claro es que las fechas a las que nos referimos coinciden con las de la Fase 2 de la Vaquera: $5800 \pm 30$ BP $(\mathrm{GrN}-22929)$ y $4850 \pm 80 \mathrm{BP}(\mathrm{GrN}-23560)$ (Estremera 1999: 249), tanto en sus momentos más antiguos, como en los más recientes, como corroboran las fechas del nivel 
I de la cámara de Azután y la de la cabaña del Castillejo. De este modo, se define bien un Neolítico Medio y Final en el que aún aparecen especies cardiales junto con incisas y bordes con surco, asociadas a una industria lítica de sustrato en la que los geométricos continúan detentando un protagonismo manifiesto. Durante su desarrollo, se detectan en la Meseta dólmenes, túmulos sin estructura megalítica, redondiles, poblados al aire libre y cuevas.

La presencia en los habitats de animales domésticos y de agricultura, junto con cerámica e instrumentos pulimentados, corrobora su adscripción a grupos de economía mixta que se desarrollan en un ambiente de dehesa, ambiente que podemos definir como un cultivo especializado de algunos sectores mediterráneos y atlánticos, en los que terrenos pobres para la agricultura sí resultan beneficiosos para el mantenimiento de una cabaña conformada por ovicaprinos, bóvidos, $\mathrm{y}$, probablemente suidos, aunque no los tenemos documentados en los yacimientos toledanos.

Estos hábitats al aire libre del Neolítico meseteño no son únicos de la zona interior y están comenzando a documentarse en la cuenca occidental del Tajo, caso de Pena d'Agua (Zilhao y Carvalho 1996), con una fecha próxima a la del nivel bajo túmulo de Azután: $5180 \pm 240$ BP (ICEN-1147) y con materiales muy similares como bordes con surco, cerámicas impresas, incisas y a la almagra y útiles líticos de sustrato. Lo mismo sucede en la cuenca del Guadiana con los núcleos de habitación que se están localizando junto a los monumentos megalíticos de Reguengos de Monsaraz (Gonçalves y Sousa 2000).

La reiteración en el uso de los mismos lugares se constata en Azután con la presencia de campaniforme marítimo y en el Castillejo, donde además de enterramientos campaniformes en el túmulo, disponemos de un enorme hábitat, el del Fontarrón y de una espectacular necrópolis de cuevas artificiales bien datadas en el IV milenio BP. Las poblaciones de las que hablamos son, por tanto, grupos asentados en el mismo territorio desde fechas antiguas del neolítico y constituyen una sólida base demográfica que relativiza sobremanera las propuestas de marginalidad cultural, que se habían sostenido sobre la base de una escasa demografía en los sectores interiores de la Península Ibérica.

\section{BIBLIOGRAFÍA}

AIRA RODRÍGUEZ, M. J.; SAA OTERO, P. y TABOADA CASTRO, T. 1989: Estudios paleobotánicos en yaci- mientos arqueológicos de Galicia. Santiago de Compostela.

APELLÁNIZ, J. M. 1973: Corpus de materiales de las culturas prehistóricas con cerámica del País Vasco meridional. Munibe. Suplemento 1.

BRIARD, J. 1995: Les mégalithes de l'Europe atlantique. Architecture et art funéraire. Ed. Errance, París.

BUENO RAMÍREZ, P. 1988: Los dólmenes de Valencia de Alcántara. Excavaciones Arqueológicas.en España 159. Madrid.

- 1990: "Megalitos en la submeseta Sur: la provincia de Toledo". I Congreso de Arqueología de la Provincia de Toledo: 126-162. Toledo.

- 1991: Megalitos en la Meseta Sur: los dólmenes de Azután y La Estrella (Toledo). Excavaciones Arqueológicas en España 159.

- 1994: "La necrópolis de Santiago de Alcántara (Cáceres). Una hipótesis de interpretación para los sepulcros de pequeño tamaño del megalitismo occidental". Boletín del Seminario de Estudios de Arte y Arqueología LX: 25-100.

- 2000: "El espacio de la muerte en los grupos neolíticos y calcolíticos de la Extremadura española: las arquitecturas megalíticas”. El Megalitismo en Extremadura. (Homenaje a Elías Dieguez Luengo). Extremadura Arqueológica VIII: 35-80.

BUENO RAMÍREZ, P. y BALBÍN BEHRMANN, R. de1996: "Dólmenes en la zona Sur de la Meseta española". U. I. S. S. P. P. Series Colloquia. Forlí, t. 9, coll. XVIII: 97-102.

- 1998: "Megalitismo en la provincia de Toledo". Homenaje de Talavera y sus tierras a D. F. Jimenez de Gregorio. Toledo: 57-70

BUENO RAMÍREZ, P.; BALBÍN BEHRMAN, R. y BARROSO BERMEJO, R. 2000a: "Restauraciòn y consolidación en yacimientos megalíticos del interior del Tajo". El Megalitismo en Extremadura (Homenaje a Elías Diéguez Luengo). Extremadura Arqueológica VIII: 425-443.

- 2000b: "Valle de las Higueras (Huecas, Toledo, España). Una necrópolis Ciempozuelos con cuevas artificiales al interior de la Península”. Estudos Prè-històricos VIII: 49-80.

BUENO, P.; BALBÍN, R.; BARROSO, R.; ALCOLEA, J.J.; VILLA, R. y MORALEDA, A. 1999: El dolmen de Navalcán. El poblamiento megalítico en el Guadyerbas. Diputación Provincial de Toledo. 136.

BUENO RAMÍREZ, P.; GONZÁLEZ CORDERO, A. y ROVIRA LLORENS, S. 2000: "Areas de habitación y sepulturas de falsa cúpula en la cuenca extremeña del Tajo. Acerca del poblado con necrópolis del Canchal, en Jaraiz de la Vera (Cáceres)". El Megalitismo en Extremadura (Homenaje a Elías Diéguez). Extremadura Arqueológica VIII: 211-244.

BUENO RAMÍREZ, P.; JIMÉNEZ SANZ, P. J. y BARROSO BERMEJO, R. 1995: "Prehistoria Reciente en el 
Noreste de la provincia de Guadalajara". En R. de Balbín, J. Valiente y M. Mussat (Coord.): Arqueología en Guadalajara: 71-95.

BUXÓ, R. 1997: Arqueología de las plantas. Crítica. Barcelona.

CARROBLES, J y MÉNDEZ CABEZA, V. 1991: "Introducción al estudio del Calcolítico en la Jara toledana". Anales toledanos XXXVIII: 7-23.

CARROBLES, J.; MUÑOZ, K. y RODRÍGUEZ, S. 1994: "Poblamiento durante la Edad del Bronce en la cuenca media del Tajo". La Edad del Bronce en Castilla-laMancha. Toledo: 173-200.

CASSEN, S.; GARNIER, B. y ROJO, M. 1993: "Un programme informatique pour la représentation graphique des séries de dates $\mathrm{C} 14$ corrigées: application aux sépultures monumentales néolithiques de la Péninsule Ibérique”. Congrés Nationales des Societés Historiques et Scientifiques 118: 499-520.

CERRILLO CUENCA, E.; PRADA GALLARDO, A.; GONZÁLEZ CORDERO, A. y HERAS MORA, F. J. 2002: "La secuencia cultural de las primeras sociedades productoras en Extremadura: una datación absoluta del yacimiento de los Barruecos (Malpartida de Cáceres. Cáceres)". Trabajos de Prehistoria 59(2):

DELIBES, G. 1995: "Ritos funerarios, demografia y estructura social entre las comunidades neolìticas de la submeseta norte". En R. Fàbregas Valcarce, Perez Losada y Fernandez Ibañez (eds.): Arqueoloxia da Morte. Xinzo de Limia: 63-95.

DELIBES, G.; ALONSO, M. y ROJO, M. 1987: “Los sepulcros colectivos del Duero Medio y las Loras y su conexión con el foco dolmènico riojano". El Megalitismo en la Península Ibérica. Madrid: 181-197.

DELIBES, G. y ROJO GUERRA, M. 1997: “C14 y secuencia megalítica en la Lora burgalesa: acotaciones a la problemática de las dataciones absolutas referentes a yacimientos dolménicos". En A. Rodríguez Casal (ed.): O Neolítico atlántico e as orixes do megalitismo. Santiago de Compostela: 391-414.

DELIBES, G. y SANTONJA, M. 1986: El fenómeno megalítico en la provincia de Salamanca. Diputación de Salamanca.

DELIBES, G. y ZAPATERO MAGDALENO, P. 1996: “De lugar de habitación a sepulcro monumental: una refexión sobre el yacimiento neolítico de la Velilla, en Osorno (Palencia)". Rubricatum I: 337-348.

DÍAZ DEL RÍO, P. 2001: La formación del paisaje agrario: Madrid en el III y II milenio BC. Arqueología, $\mathrm{Pa}-$ leontología y Etnografía 9.

ETXEBERRÍA GABILONDO, F. y DELIBES DE CASTRO, G. 2002: "Interpretación del fuego en los sepulcros megalíticos". En M. Rojo Guerra y M. Kunst (eds.): Sobre el significado del fuego en los rituales funerarios del Neolítico. Studia Archaeologica, 91.

FABIÁN GARCÍA, J. F. 1992: "El enterramiento campaniforme del Túmulo 1 de Aldeagordillo (Avila)". Bole- tín del Seminario de Estudios de Arte y Arqueología. LVIII: 97-132.

FERNÁNDEZ-POSSE, Ma . D. 1980: "Los materiales de la Cueva del Aire de Patones (Madrid)". Noticiario Arqueológico Hispánico 10: 39-64.

HIGGS, E. y VITA FINZI, C. 1972: "Prehistoric economies: a territorial aproach". Papers in Economic Prehistory.

GALERA, V. 1991: "Estudio antropológico". En P. Bueno Ramírez: Megalitos en la Meseta Sur: los dólmenes de Azután y la Estrella (Toledo). Excavaciones Arqueológicas en España 159. Madrid: 51-57.

GONÇALVES, V. S. y SOUSA, A. C. 2000: "O grupo megalítico de Reguengos de Monsaraz e a evoluçao do megalitismo no Occidente peninsular (espaços de vida, espaços da morte: sobre as antigas sociedades camponesas em Reguengos de Monsaraz)". Trabalhos de Arqueología 16: 11-104.

JEUNESSE, CH. 1997: Pratiques funéraires au Néolithique ancien. Sépultures et nécropoles danubiennes 5500-4900 av. J-C. Ed. Errance. París.

KUNST, M. y ROJO GUERRA, M. 1999: "El Valle de Ambrona: un ejemplo de la primera colonización Neolítica de las tierras del Interior Peninsular". II Congrés de Neolitic a la Península Ibérica. Saguntum. Extra-2: 259-270.

MARTÍNEZ NAVARRETE, M. I. 1984: "El comienzo de la metalurgia en la provincia de Madrid: la cueva y cerro de Juan Barbero (Tielmes, Madrid)". Trabajos de Prehistoria 41: 17-91.

MONTERO RUIZ, I.; RODRÍGUEZ MONTERO, S. y ROJAS RODRÍGUEZ-MALO, J. M. 1990: Arqueometalurgia de la provincia de Toledo: minería y recursos minerales de cobre. Diputación Provincial de Toledo. Toledo.

OSUNA RUIZ, M. 1975: "El dolmen del "Portillo de las Cortes" (Aguilar de Anguita. Guadalajara)". Noticiario Arqueológico Hispánico. Prehistoria, 3: 237-309.

PALOMINO LÁZARO, A. L. y ROJO GUERRA, M. 1997 : "Un nuevo yacimiento neolítico de habitación infratumular: "El Teso del Oro", en San Martín de Valderaduey (Zamora)". En R. de Balbín, P. Bueno (eds.): II Congreso de Arqueología Peninsular. II: Neolítico, Calcolítico y Bronce. Fundación Rei Afonso Henriques. Zamora: 249-256.

ROJO GUERRA, M. y ESTREMERA PORTELA, S. 2000: "El Valle de Ambrona y la cueva de la Vaquera: testimonios de la primera ocupación neolítica en la cuenca del Duero". Neolitizaçao e megalitismo da Península Ibérica. ADECAP. Porto: 81-96

ROJO GUERRA, M. A. y KUNST, M. (eds.) 2002: Sobre el significado del fuego en los rituales funerarios del Neolítico. Studia Archaeologica 91.

ROJO GUERRA, M.A.; KUNST, M. y PALOMINO LÁZARO, A. 2002: "El fuego como procedimiento de clausura en tres tumbas monumentales de la Subme-

T. P., 59, n. ${ }^{\circ} 2,2002$ 
seta Meseta Norte". En Rojo y Kunst (eds.): Sobre el significado del fuego en los rituales funerarios del Neolítico. Studia Archaeologica, 91: 21-38.

SENNA-MARTÍNEZ, J. C. 1996: "Pastores, recolectores e constructores de megalitos na Plataforma do Mondego nos IV e III milenios AC: O sitio de Ameal VI". Trabalhos de Arqueologia de EAM 3/4: 83-122.

TERRAL, J. F. 1993: Olivier sauvage et Olivier cultivé: approche pour l'analyse minérale du bois, application à du matérial anthracologique. Diplome d'Etudes Approfondies. Université Montpellier II.

- 2001: "Biomètrie et archeobotanique: des nouvelles approches bioarcheologiques". Seance de la Societe Préhistorique Française, 19-mai. 2001, organisè par P. Marinval. Comptes Rendus. Bulletin de la Societé Préhistorique Française 98(4): 744.

ZAPATERO MAGDALENO, P. 1991: "Sobre las relaciones entre neolítico interior y megalitismo". Boletín del Seminario de estudios Arte y Arqueologìa LVII: 53-61.

ZILHÃO, H. y CARVALHO, A. F. 1996: "O Neolitico de o Maciço calcário Estremenho: crono-estratigrafía e povoamento". I Congrés del Neolitic a la Península Ibérica. Rubricatum I(2): 659-671. 